Daniel Garibaldi.

"DESTINO DE COLMENA. CONTROL SOCIAL Y POLICÍA"

Editorial Bilbos, 2012.

\title{
Destino de colmena. Control Social y Policía
}

El autor desarrolla el libro en seis apartados: Introducción; el concepto de policía de seguridad; el rol del Estado en lo atinente a seguridad; el Estado y la justificación de la coacción pública; los límites de la coacción estatal y conclusiones.

En la introducción el autor define al control social como los métodos que la sociedad utiliza para asegurar que sus miembros respondan al orden social dominante; además identifica tres dimensiones de control social, la primera dimensión es el autocontrol, y consiste en que el individuo regule sus propios comportamientos y deseos; la segunda dimensión es el control social informal u oficioso, el cual es un tipo de control derivado del sistema de valores y costumbres dominantes en la sociedad; finalmente, la tercera dimensión es el control formal, y representa la institucionalización del control social, lo realizan agentes especializados y se legitima en los sistemas normativos.

En el apartado "El concepto de policía de seguridad", se establece que el objeto-policía es un aparato más de los que el Estado utiliza para mantener el poder y garantizar el control social; se coloca a la policía como una pequeña parte dentro de los procesos de control social; se le asignan a la policía tres tipos de funciones generales, de las cuales se derivan otra serie de actividades, estas son: aplicar la ley, mantener el orden y prestar servicios a la comunidad.

En el tercer apartado denominado "El rol del Estado en lo atinente a la seguridad", se presenta una cronología del desarrollo a través de la historia del papel que ha jugado el Estado en diferentes momentos en temas de seguridad; el autor define en este apartado la relación penalpolicial, en el que destaca que el pensamiento penal se abrió con la revolución industrial, con el surgimiento de una clase social interesada en limitar el poder punitivo ejercido por la nobleza; se retoma el tema de la urbanización y sus conflictos, en el que se destaca que la atención del Estado se centró en torno al control de la calle y de los grupos marginados, quienes representaban el mayor peligro para la sociedad de la época. 


\section{LIBROS}

En "El Estado y la justificación de la coacción pública" se afirma que con el inicio del liberalismo se dio el paso de una sociedad estamental a una sociedad clasista, lo que en el plano jurídico significó la instauración del Estado de derecho como nuevo sistema; se impuso este nuevo sistema con el objetivo de garantizar el libre desarrollo económico de la burguesía, lo que les permitió elevar el derecho a la propiedad a la categoría de "derecho sagrado e inviolable", a tal grado que los códigos penales liberales castigaban con las mayores penas a los delitos que atentaban contra el sistema de libertades y contra la propiedad privada.

En el quinto apartado "Los límites de la coacción estatal", el autor plantea que los límites del Estado para coaccionar a las personas son difusos, ya que cuenta con los medios y herramientas necesarias para llevar la legalidad a los límites que considere necesarios para el logro de sus objetivos. Además, se afirma que en momentos de bienestar económico de los Estados, disminuyen los gastos en justicia y se aumentan los gastos en educación y asistencia social y viceversa.

El autor concluye que para el Estado moderno, garantizar la seguridad de las personas es su total responsabilidad, limitando con esto la capacidad de las personas de resolver sus conflictos. Esto se adecuará siempre a las necesidades y beneficios de quienes estén en el poder en un momento determinado y el control que tengan estos grupos sobre las instituciones encargadas de establecer el orden público.

El libro resulta relevante y de fácil lectura puesto que plantea de manera concisa los elementos fundamentales del control social y su desarrollo a través de diversos acontecimientos históricos.

Sinopsis a cargo de Alejandra Patricia Gutiérrez Portillo Centro de Investigación Científica 